\title{
A PROCESS MODEL OF PRODUCT PLATFORM BUILDING FOR THE PRODUCTS WITH THE SAME FUNCTION STRUCTURE
}

\author{
Huangao Zhang ${ }^{1}$, Wenyan Zhao ${ }^{2,3}$, Guoping $\mathrm{Li}^{1,4}$, Runhua Tan ${ }^{1}$ \\ ${ }^{\prime}$ School of Mechanical Engineering, Hebei University of Technology, Tianjin, 300130, \\ PRC ; Email: zhgzwv@evou.com ${ }^{2}$ School of Management, Tianjin University, Tianjin, \\ 300072, PRC ${ }^{3}$ School of Management, Hebei University of Technology, Tianjin, 300130, \\ PRC, 'Zhangjiakou Coal Mining Machinery Co. Ltd, Zhangjiakou,075025, PRC;
}

Abstract: Product platform is a good way to achieve Mass Customization. The ability of deriving variants of a product platform depends on its configuration, which ultimately is determined by voices of customer. The nature of product platform building is to identify the common parts from the object product family. According to the similarity of a set of products the product platform divided into two cases: similar function with close parameters and same function with different parameters. Based on E-QFD a process model of product platform building for the last case is put forward that start from analyzing customers' demands. And the steps according to the process model are discussed. As an illustration the model is applied to build the product platform for armed face conveyer.

Key words: product platform; HOQ; customers' demands; technical measure; module; armed face conveyer(AFC)

\section{INTRODUCTION}

Product platform is a good way to achieve Mass Customization. A welldefined product platform can succeed in the purpose that the company can provide as much variety as possible for market with as little variety as possible between products.(Mayer, 1997)

Considering the similarity of a set of products the product platform can include two cases:

Please use the following format when citing this chapter:

Zhang, Huangao, Zhao, Wenyan, Li, Guoping, Tan, Runhua, 2006, in International Federation for Information Processing (IFIP), Volume 207, Knowledge Enterprise: Intelligent Strategies In Product Design, Manufacturing, and Management, eds. K. Wang, Kovacs G., Wozny M., Fang M., (Boston: Springer), pp. 1002-1009. 
- Product platform for a set of products with similar function and close parameters. Similarity of function is that a set of products vary in functions but share several items such as input and output in their function structure chart, for example the truck and the bus has the same input and output and then their function is similar. (McAdams, 1997) Just those common parts make it possible for the objective products to build a product platform, because the common function model can be implement by the same concept solution, furthermore, the close parameters of the function give more chances to use the same physical model to implement the common concept solution. The main problem of this case for product platform building is to identify the common function models.

- Product platform for a set of products with same function and different parameters. The same function means a set of products have the same function structure chart while their performance parameters are different. At this case the objective products used to be classified into family tree according to their main parameters. (Javier, 2000) There are good chances in each branch to build a platform. And there always have chance to build a platform which can cover several branch. The main problem of this case is to identify the main parameters and common parts of each branch. Next parts a process model will be discussed for product platform building in this case.

\section{A PROCESS MODEL FOR PRODUCT PLATFORM BUILDING}

Good product platforms must be carefully planned, designed, and developed. This requires intimate knowledge of customer requirements and a thorough understanding of the market. (Simpson, 1998) As shown in figure 1, a process model for product platform building is developed that start from the customers' demands and end with platform configuration. The model extends QFD (E-QFD) to identify the common parts of a set of product with the same function.

According to the model the general steps will be included as follows:

\section{Step1. Identify and Analyze the Demands of Customers}

Customers' demands can be collected by market research. The demands should be classified into two types: basic demands and special demands.

- Basic demands are the demands that the customers desire for the main function and primary performance of the products. Generally, basic 
demands include power, kinetic and dynamic index, essential function, reliability, life, important dimension and structure parameters and so on.

- Special demands are the demands other than basic demands. Special demands usually include three aspects: additional function desired by customers, additional requirements for adapt to different object and environment, other demands result in irregular change in parameter of performance and architecture. If the products should attract customers and carry out their function perfectly, the special demands must be met.

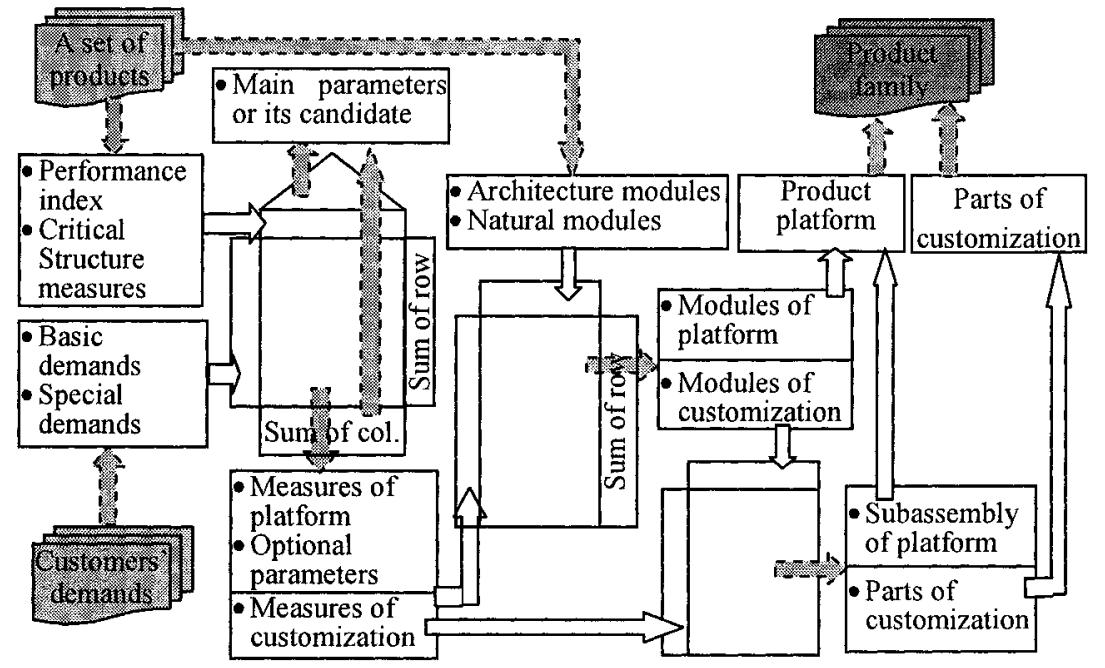

Figure l.a process model for product platform building

\section{Step2. Select Technical Measures of the Object Product Family}

According to the product object the performance measures and critical structure measures could be identified. The performance measures represent the function and capability of the product, such as Power, velocity etc. And the critical structure measures are items of measure that must be decided before the detail design begin. The measures rest with the interior and exterior demands, such as capability, environment restriction and so on.

\section{Step3. Identify the Measures Respectively Belong to Platform and Customization}

The HOQ is developed to relate the customers' demands and the technical measures. (Jack, 1997) The sums are calculated for each column and each row in the relationship matrix. An item of customers' demands with higher sum value of each row has more influence on the technical measures than other items. The weights that represent relative importance of each demand can be given according as the sum of the row. The technical 
measures with higher sum value of each column could be select to be main parameters candidate according to which the product family tree is plotted.

Those technical measures that relate to basic demands while didn't relate to special demands are ranged in the measures of product platform. Some other technical measures whose value can be selected from a few of constant value are classified into the optional parameters. The rest of technical measures should are defined as the measures of customization, which will influence on the structure and parameters of the parts of customization.

The roof of the HOQ is the correlation matrix that describes the relationships between technical measures. The items that correlate to most of the others should be main parameter candidates.

\section{Step4. Model Analysis for Function and Architecture}

First, define the general function according to customers' demands. Second, implement function analysis and obtain function configuration chart. Third, identify the function module according to three-flow-principle. (Stone, 1997) Fourth, implement architecture analysis according to architecture of the object product family and function module. At last the architecture modules of the object product family can be identified. Note that the components can be used as the natural modules of the object product family. The architecture modules identified can be used as the initial module of modularization design for product platform.

\section{Step5. Identify the Modules Belong to Platform}

The second HOQ is developed to relate the technical measures and architecture modules of the object product family. The sums are calculated for each row in the relationship matrix. Those technical measures with higher value of sum of each row are main parameter candidates.

Those modules having no relation to measures of customization will be ranged in modules of product platform. Some of them that associate with optional parameters are modules belong to multi-platform.

The modules associated with the measures of customization are modules of customization, two cases would include:

- If the module is a part, the part is module of customization.

- If the module is a component or assembly, the component or assembly should be analyzed further for the further processing.

\section{Step6. Identify the Parts or Sub-assembly of Platform from Modules of Customization}

First, the component or assembly of customization is disassembled into parts. Second, the HOQs are developed to relate the measures of 
customization and the parts for each component or assembly of customization. Third, identify the parts out of product platform. The parts have relation to measures of customization are parts out of platform that must be designed for each product. Others can be assembled into subassembly and add to product platform.

\section{Step7. Integrate and Redesign Modules}

The modules of platform identified in step 5 and sub-assembles or parts of platform identified in step 6 combined into the product platform of the object product family. All elements are prescribed by synthesized attributes that include measure, shape, material and so on and integrated into a database of product platform. The parts of customization are redesigned according to the method of broad-sense-modularization so that the change is the least when the parts are used as prototypes for redesign. According to existing products the interfaces between modules are redesigned for standardization.

\section{AN EXAMPLE}

Armored face conveyer (AFC) is typical product for customization. Most AFC design is variants design that the variant use an existing product as a prototype. There are many common parts between different variant. AFC is a type of product with same function, and its variants can be compartmentalized in series. The above-mentioned process model is applied to build the product platform for AFC.

As shown in figure 2, the customers' demands and technical measures are integrated in HOQ1. The demands in the shadow are special demands, and other demands are basic demands. The A1-matrix is evaluated according to the strength of relationship between customers' demands and technical measures: (Jack, 1997)

- Strong=5. The strength is strong when the value of the technical measure is determined directly by the customer's demand.

- Medium=3. The strength is medium when the customer's demand influences the value of the technical measure indirectly.

- Weak $=1$. The strength is weak when the technical measure has some relation with the customer's demands and the value of the measure can be selected in a broad range.

- Blank=0. An item of the A1-matrix is blank, which represent the technical measure has no relation with the customer's demand.

In the roof of HOQ1, " $+"$ represents that the two technical intersected at the position correlate to each other. 


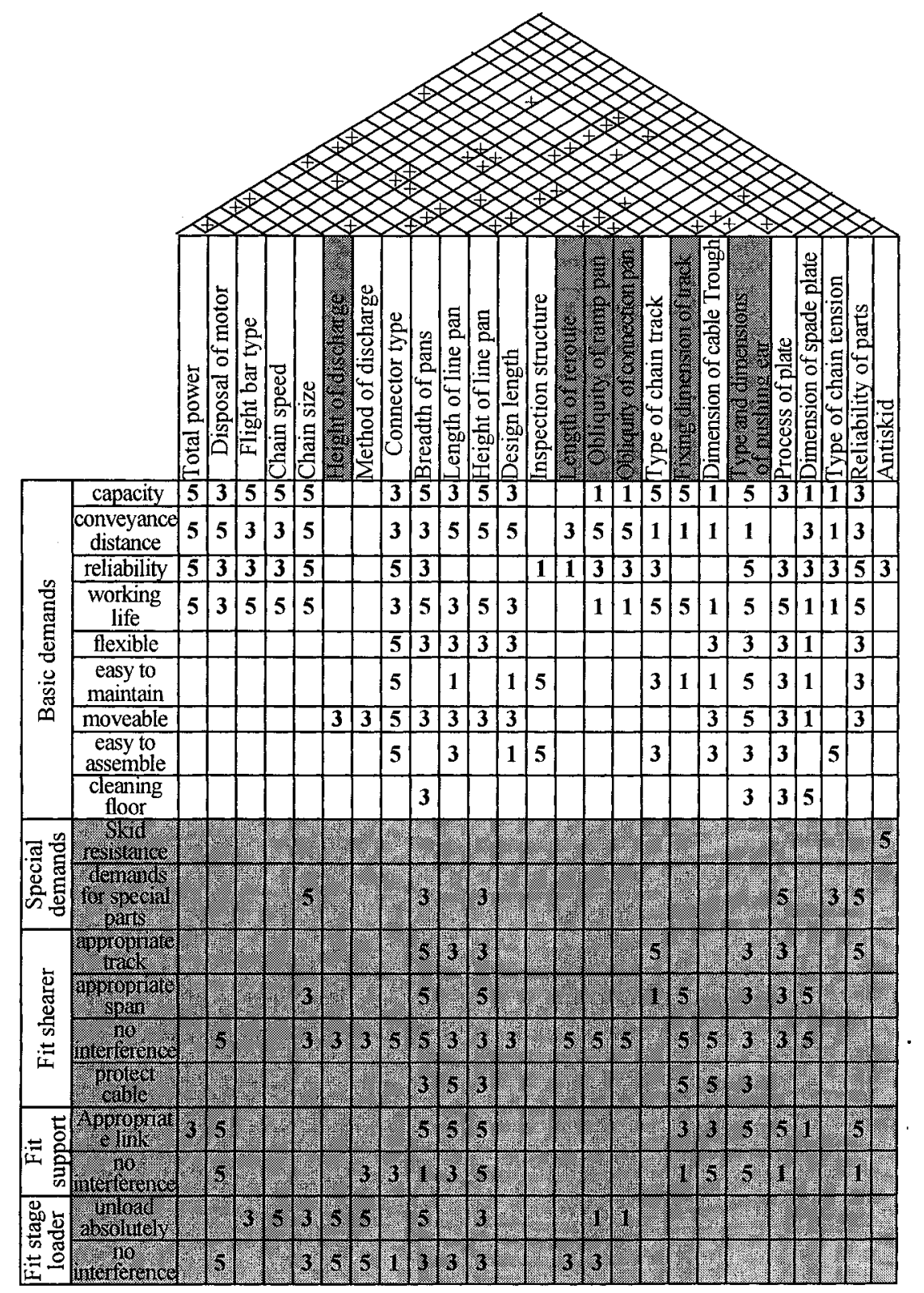

Figure2.a process model for product platform building 
In the technical measures associated with the special demands the height of discharge, the length of re-route, obliquity of ramp pan, obliquity of connection pan, fixing dimension of track, the type and dimensions of pushing ear can not be fixed. The other technical measures associated with the special demands are the optional parameters.

As shown in table 1, the technical measures and module of AFC are integrated in HOQ2. The modules in the house are components for field installation. From the table we can see that the breadth of pan correlate to most modules, which confirm the conclusion that the breadth is the main parameters for AFC family tree analysis. If ignore some fringe demands, the transmission unit of delivery end and return end can add to platform directly. In view of the seat of track and spilling plate are joined by weld, the track assembly can add to platform directly too. Ignore the weak relation the chain assembly that includes chain, flight bar assembly and chain connector can also add to platform directly. The other module should be analyzed further to find invariant parts for platform. As an example the line pane is analyzed further into four parts: spade plate, spilling plate, deck plate and bottom plate. Only spilling plate relate with the measure of customization, then the other three parts integrate into a sub-assembly and add to the product platform.

Table 1, the HOQ2 that relate the technical measures to module of AFC

\begin{tabular}{|c|c|c|c|c|c|c|c|c|c|c|c|c|c|c|c|}
\hline & 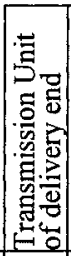 & 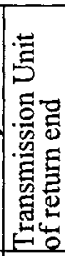 & 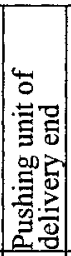 & 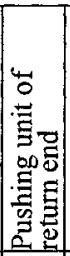 & 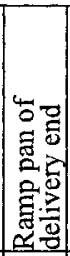 & 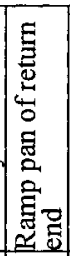 & 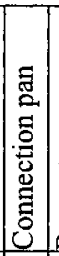 & 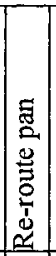 & 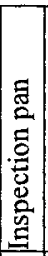 & 胥 & 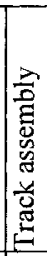 & 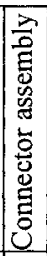 & 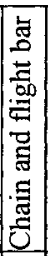 & $\begin{array}{c}0 \\
010 \\
\tilde{0} \\
0 \\
0 \\
0 \\
0 \\
0 \\
\end{array}$ & 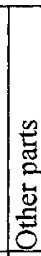 \\
\hline Total power & 5 & 5 & 3 & 3 & 3 & 3 & 3 & 3 & 3 & 3 & 1 & 3 & 5 & & \\
\hline Disposal of motor & 5 & 5 & 3 & 3 & & & & & & & & & & & \\
\hline Flight bar type & 5 & 5 & & & 5 & 5 & 5 & 5 & 5 & 5 & 1 & 3 & 5 & & \\
\hline Chain speed & 3 & 3 & 1 & 1 & 1 & 1 & 1 & 1 & 1 & 1 & & & 5 & & \\
\hline Chain size & 5 & 5 & 5 & 5 & 5 & 5 & 5 & 5 & 5 & 5 & 3 & 3 & 5 & 3 & 1 \\
\hline Meigh of uiscliaroe & 2 & 20 & 5 & 3 & 5 & 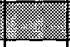 & 5 & $\sqrt{3}$ & & 10 & 10 & 12) & 1 & 5 & \\
\hline Method of discharge & 5 & 5 & 5 & & 3 & & 3 & 3 & & & & & & & \\
\hline Connector type & 5 & 5 & & & 5 & 5 & 5 & 5 & 5 & 5 & 1 & 5 & 1 & & \\
\hline Breadth of pans & 5 & 5 & 5 & 5 & 5 & 5 & 5 & 5 & 5 & 5 & 3 & 3 & 3 & 3 & 1 \\
\hline Length of line pan & & & & & 3 & 3 & 5 & 5 & 5 & 5 & & 3 & 3 & 5 & \\
\hline Height of line pan & 3 & 3 & & & 5 & 5 & 5 & 5 & 5 & 5 & 3 & 3 & 5 & 3 & \\
\hline Design length & 5 & 5 & & & 5 & 5 & & 3 & & & & & & 5 & \\
\hline Inspection structure & & & & & & & & & 5 & & & & & & \\
\hline Pengh of reroule & & en: & & & 5 & 8 & 3 & 5. & & 1 & & & & & \\
\hline Obliquy or tarep & & 2 & is & & 3 & 8 & 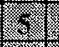 & 15 & & 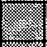 & & & 1. & & \\
\hline 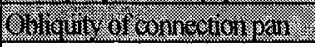 & ; & 3 & & & 3 & 3 & 3 & 3 & & & & 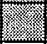 & 18 & & \\
\hline Type of chain track & & & & & & & & & & & 5 & & & & \\
\hline
\end{tabular}



the Same function Structure

\begin{tabular}{|c|c|c|c|c|c|c|c|c|c|c|c|c|c|c|c|}
\hline 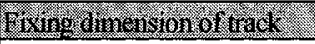 & & 2 & & & 3 & (3) & & 5 & & 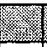 & 5 & & 1 & 3. & \\
\hline Dimension of cable Trough & & & & & & & & & & & 3 & & 3 & 5 & \\
\hline $\begin{array}{l}\text { Y Ype and dinensions of } \\
\text { pristing er }\end{array}$ & & & 8. & 8 & 5 & f. & 3 & 5 & 5 & 15 & 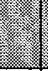 & 1 & 1 & 1 & \\
\hline Process of plate & & & & & & & 5 & 5 & 5 & 5 & 3 & 3 & 3 & & \\
\hline Dimension of spade plate & & & & & 3 & 3 & 3 & 3 & 5 & 5 & & & 1 & & \\
\hline Type of chain tension & 5 & 5 & & 5 & & 5 & & & & & & & & & \\
\hline Reliability of parts & 5 & 5 & 3 & 3 & & & & & & & 3 & 3 & 5 & & \\
\hline Antiskid & & & & & 3 & 3 & 3 & 3 & 5 & 5 & & & & & \\
\hline
\end{tabular}

\section{SUMMARY}

Product platform is a set of modules or parts shared by a set of products. The nature of product platform building is a process that the common items are identified by some means. A process model of building product platform has been presented. This model takes into account voice of customers and restrictions of environment, and is propitious to build product platform for the products with the same function structure.

The process model shown in this paper has been applied to a set of AFC. The elements of platform are identified. It will help many enterprises to realize mass customization.

\section{ACKNOWLEDGMENT}

The research is supported in part by Natural Science Foundation of China under Grant Numbers 50375045 and TianJin Natural Science Foundation Key Projects under Grant Number 043802211.

\section{REFERENCES}

1. Meyer M H, Lehnerd A P, 1997, The power of product platforms, USA, Free Press, New York

2. Simpson T. W., 1998, A Concept Exploration Method for Product Family Design, Ph. D Dissertation, Georgia Institute of Technology

3. McAdams D A, Stone R B, 1998, Wood K L. Understanding Product Similarity Using Customer Needs, ASME Design Engineering Technical Conference, DETC98/DTM-5660

4. Javier P. Gonzalez-Zugasti, 2000, Kevin N. Otto, John D. Baker, A Method for Architecting Product platforms, 12, Research in Engineering Design, pp.61-72

5. Stone R. B., 1997, Towards a Theory of Modular Design, Ph. D Dissertation, University of Texas

6. Jack B. Revelle, John W. Moran, Charles A. Cox, 1998, The QFD Handbook, USA: John Wiley \& Sons, Inc., New York, pp.3-21. 